\title{
Enantioseletive bioaccumulation of tebuconazole in earthworm Eisenia fetida
}

\author{
Dingyi Yu, Jianzhong Li*, Yanfeng Zhang, Huili Wang, Baoyuan Guo*, Lin Zheng \\ Research Center for Eco-Environmental Sciences, Chinese Academy of Sciences, Beijing 100085, China. E-mail: yudingyi1990@ sina.com.cn
}

Received 09 February 2012; revised 16 March 2012; accepted 28 March 2012

\begin{abstract}
Methods of extraction and determination of tebuconazole enantiomers in earthworm (Eisenia fetida) were developed by capillary electrophoresis (CE) and high performance liquid chromatography (HPLC). Both CE and HPLC have excellent resolution and recovery. The linearity ranges were $2.9-102.4 \mathrm{mg} / \mathrm{kg}$ and 3.0-99.6 mg/kg for (+)-R-tebuconazole and (-)-S-tebuconazole respectively in CE, and from 0.56 to $1000 \mathrm{mg} / \mathrm{kg}$ for both enantiomers in HPLC. Enantioselective bioaccumulation in earthworms from soil was investigated under laboratory condition at concentrations of 10 and $50 \mathrm{mg} / \mathrm{kg} \mathrm{dw}$ in soil. The uptake kinetics of (+)-R-tebuconazole fitted the firstorder kinetics well with $r^{2} 0.97$ and 0.94 under 10 and $50 \mathrm{mg} / \mathrm{kg} \mathrm{dw}$ exposure condition, respectively, while (-)-S-tebuconazole with $r^{2}$ 0.75 and 0.22 did not show the same. Bioaccumulation of tebuconazole in earthworm tissues was enantioselective with a preferential accumulation of (+)-R-tebuconazole. The (+)-R-tebuconazole might also have biomagnifying effect potential in earthworm food chain with biota-sediment accumulation factor (BSAF) of $1.64 \mathrm{~kg} \mathrm{OC} / \mathrm{kg}$ lip in $10 \mathrm{mg} / \mathrm{kg} \mathrm{dw}$ exposure group and $2.61 \mathrm{~kg} \mathrm{OC} / \mathrm{kg}$ lip in $50 \mathrm{mg} / \mathrm{kg} \mathrm{dw}$ exposure group from soil to earthworm after 36 days. Although (-)-S-tebuconazole shares the same physicochemical properties with (+)-R-tebuconazole, it did not biomagnify. BSAFs of (-)-S-tebuconazole were $0.50 \mathrm{~kg} \mathrm{OC} / \mathrm{kg} \mathrm{lip}(10 \mathrm{mg} / \mathrm{kg} \mathrm{dw}$ tebuconazole exposure) and $0.28 \mathrm{~kg} \mathrm{OC} / \mathrm{kg}$ lip $(50 \mathrm{mg} / \mathrm{kg} \mathrm{dw}$ tebuconazole exposure) after 36 days, which was possibly owing to biotransformation or metabolism in earthworm tissues.
\end{abstract}

Key words: tebuconazole; earthworm; bioaccumulation; enantioselectivity

DOI: $10.1016 / \mathrm{S} 1001-0742(11) 61053-\mathrm{X}$

\section{Introduction}

It has been reported that more than $25 \%$ of pesticides are chiral compounds with at least two mirror image enantiomers (Williams, 1996). Enantiomers usually differ in their biological properties such as bioactivity, toxicity, metabolism, accumulation and degradation behaviors due to their interaction with enzymes or other naturally occurring chiral molecules (Hegeman and Laane, 2002). Triazole derivatives represent an important category of fungicides, and chirality is almost ubiquitous among them (Wu et al., 2001). Tebuconazole, (RS)-1-p-chlorophenyl)-4,4dimethyl-3-(1H-1,2,4-triazol-1-ylmethyl)pentan-3-ol, is a broad-spectrum triazole fungicide used to control soilborne and foliar diseases in peanuts and other crops. Tebuconazole has one chiral carbon atom and a pair of enantiomers as shown in Fig. 1. Its absolute configuration is left-optical (-) rotation of S-enantiomer and rightoptical (+) rotation of R-enantiomer (Kaulen, 1989). The $(+)$-R-enantiomer shows faster degradation than that of (-)-S-enantiomer in cabbage, rat liver microsomes and rabbit plasma, while (-)-S-enantiomer dissipates faster than (+)-R-form in cucumber fruit and soil (Zhu et al., 2007; Shen et al., 2012; Wang et al., 2012). It is important to

* Corresponding author. E-mail: jzli@rcees.ac.cn (Jianzhong Li); guoby@rcees.ac.cn (Baoyuan Guo)

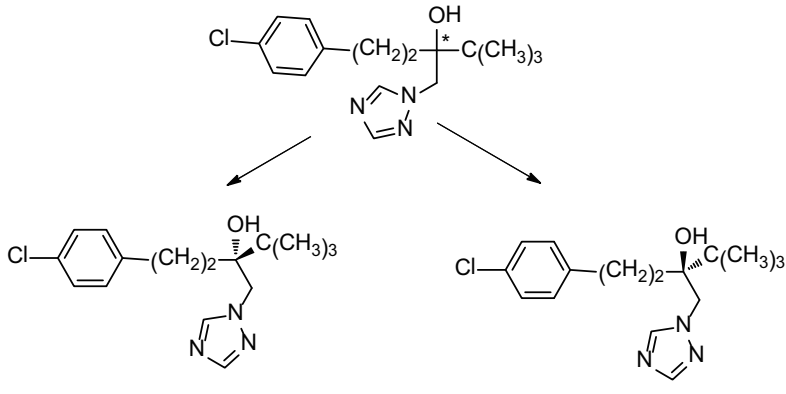

(-)-S-tebuconazole

(+)-R-tebuconazole

Fig. 1 Chemical structures of two enantiomers from tebuconazole.

further understand the biological behavior of tebuconazole enantiomers in ecosystem.

Earthworms are exposed to a wide variety of agricultural chemicals such as insecticides, fungicides and herbicides and are recognized as effective indicators of environmental pollution. Earthworms are appropriate model organisms for bioavailability as they live in close contact with the soil, have a thin and permeable cuticle, and also consume large amounts of soil (Jager et al., 2005). Environmental Protection Agency, Organization for Economic Cooperation and Development, and Ministry of Agriculture of the People's Republic of China have already used the earthworm (Eisenia fetida) as an indicator organism to assess the potential biological effect of the chemicals if released into 
the environment. Equilibrium partitioning theory model has been developed to assess the bioaccumulative potential of commercial chemicals (Connell and Markwell, 1990; Armitage and Gobas, 2007). Enantioselective toxicity and bioaccumulation of pesticides in earthworms have got wide attentions in recent years. Alpha-cypermethrin (Diao et al., 2011), metalaxyl (Xu et al., 2011), and benalaxyl (Xu et al., 2009) were demonstrated to bioaccumulate enantioselectively in earthworm tissues.

Tebuconazole is often used as a seed coating agent applied in agricultural soil, therefore, earthworms may be exposed to tebuconazole of high dose directly. No research has yet been reported for bioactivity of tebuconazole enantiomers in earthworms. In this article, an effective method was developed to determine enantiomers of tebuconazole in earthworm samples by capillary electrophoresis (CE) and high performance liquid chromatography (HPLC). The enantioselective bioaccumulation of tebuconazole in earthworm (Eisenia fetida) from soil was investigated under laboratory conditions.

\section{Materials and methods}

\subsection{Chemicals and reagents}

Tebuconazole (purity $>98.8 \%$ ) was donated by Institute for the Control of Agrochemicals, Ministry of Agriculture. Stock solutions of tebuconazole were prepared in acetone at 1000 and $5000 \mathrm{mg} / \mathrm{L}$ and kept in darkness under refrigeration at $4^{\circ} \mathrm{C}$.

Water was purified by a Milli-Q system (Millipore, USA). Methanol (HPLC grade), $n$-hexane (HPLC grade) and 2-propanol (HPLC grade) were obtained from Dikma Company (USA). Acetone, petroleum ether, acetonitrile (analytical grade), sodium dodecyl sulfate (SDS), sodium hydroxide $(\mathrm{NaOH})$, potassium hydroxide $(\mathrm{KOH})$, phosphoric acid $\left(\mathrm{H}_{3} \mathrm{PO}_{4}\right)$, potassium dihydrogen phosphate $\left(\mathrm{KH}_{2} \mathrm{PO}_{4}\right)$ and urea were purchased from Beijing Chemical Reagent Co. Ltd. (China). Sulfated $\beta$-cyclodextrin (S- $\beta-C D$, typical degree of substitution, 7-11) was obtained from Fluka (Schnelldorf, Germany).

\subsection{Earthworms}

Mature earthworms (Eisenia fetida) purchased from northeastern farm, Beijing, were maintained in a wooden breeding box $(60 \mathrm{~cm} \times 50 \mathrm{~cm} \times 40 \mathrm{~cm})$ containing a mixture of soil and cattle manure. The earthworms were healthy and active before introduced into the experiment.

\subsection{Apparatus}

The CE experiments were carried out on a Beckman P/ACE MDQ Capillary Electrophoresis System (Beckman, USA) equipped with a UV detector. The electropherograms were recorded and integrated by an IBM PC running 32 Karat software version 4.0 (Beckman, USA). Separation was performed in a bare fused-silica capillary (Yongnian Optical Fiber, China) with a total length of 50 $\mathrm{cm}$ (40 cm effective length) and an inside diameter of 75 $\mu \mathrm{m}$.
The HPLC experiments were performed using an Agilent 1100 Series HPLC (Agilent, USA) equipped with G1322A degasser, G1311A pump and G1314B VWD. AT-930 heater and cooler column attemperator (Tianjin Automatic Science Instrument Co., Ltd., China) was used to control column temperature. The signal was received and processed by Agilent chemstation software.

\subsection{Capillary electrophoresis conditions}

A new capillary was initially washed with methanol for 10 min, followed by ultrapure water for $5 \mathrm{~min}, 1 \mathrm{~mol} / \mathrm{L} \mathrm{HCl}$ for $10 \mathrm{~min}$, ultrapure water for $5 \mathrm{~min}, 1 \mathrm{~mol} / \mathrm{L} \mathrm{NaOH}$ for $10 \mathrm{~min}$, and ultrapure water for $5 \mathrm{~min}$. As a daily routine procedure, the capillary was rinsed with $1 \mathrm{~mol} / \mathrm{L} \mathrm{NaOH}$ for $10 \mathrm{~min}$ followed by a 10-min rinse with ultrapure water, and then flushed with running buffer for $3 \mathrm{~min}$ before sample injection. Before each run, the capillary was rinsed with $1 \mathrm{~mol} / \mathrm{L} \mathrm{NaOH}$ for $2 \mathrm{~min}$, ultrapure water for $2 \mathrm{~min}$, and running buffer for $2 \mathrm{~min}$. To achieve reproducible separations, all experiments were performed at $(20 \pm 0.1)^{\circ} \mathrm{C}$ and were run in triplicate.

The optimal background electrolyte (BGE) in the CE experiments was $20 \mathrm{mmol} / \mathrm{L} \mathrm{KH}_{2} \mathrm{PO}_{4}$ and $10 \mathrm{mmol} / \mathrm{L}$ $\mathrm{H}_{3} \mathrm{PO}_{4}$ ( $\mathrm{pH} 2.16$ ), containing $1 \% \mathrm{~S}-\beta-\mathrm{CD}$ and $2 \mathrm{~mol} / \mathrm{L}$ urea. The running buffer was filtered with a $0.22 \mu \mathrm{m}$ filter before use. The power supply was operated in the reversedvoltage mode and the analyte migrated toward the positive pole. The separation voltage was $-25 \mathrm{kV}$, and sample injection was performed hydrodynamically under pressure of $3.45 \mathrm{kPa}$ for $5 \mathrm{sec}$, corresponding to an injection volume of approximately $5 \mathrm{~nL}$. The UV detection wavelength was set at $220 \mathrm{~nm}$.

\subsection{HPLC Conditions}

A commercial HPLC cartridge ChiralPAK IC (cellulose tris-(3, 5-dichlorophenyl-carbamate)) was used to separate tebuconazole. The cartridge purchased from Daicel Chemical Industries (Tokyo, Japan) was $250 \mathrm{~mm} \times 4.6 \mathrm{~mm}$ i.d. with the cellulose tris (3,5-dichlorophenyl polymer) immobilized on a 5- $\mu \mathrm{m}$ silica gel substrate. A mixture of $n$-hexane and 2-propanol (90:10, $V / V)$ was used as mobile phase at a rate of $1.0 \mathrm{~mL} / \mathrm{min}$. The injection volume was $20 \mu \mathrm{L}$ and the UV detection wavelength was set at $220 \mathrm{~nm}$. To achieve reproducible separations, all experiments were performed at $(20 \pm 0.1)^{\circ} \mathrm{C}$ and were run in triplicate.

\subsection{Sample treatment}

\subsubsection{Soil collection and earthworm exposure}

Surface soils $(0-10 \mathrm{~cm})$ were collected from a farm in Changping District, Beijing, China and detected no tebuconazole residue. The soil samples were sieved $(2 \mathrm{~mm})$ and air-dried at room temperature and stored in a dark dry place before experiments. Physicochemical properties of the soil were as follows: organic matter (OM), $2.00 \%$; clay, $2.73 \%$; sand, $62.29 \%$; silt, $32.98 \%$; water holding capacity, $25 \%$; and $\mathrm{pH} 7.5 \pm 0.2$ (determined according to GB 156181995).

The experiment was carried out in two levels: soil of each level was contaminated with 10 and $50 \mathrm{mg} / \mathrm{kg} \mathrm{dw}$ 
(dry weight) tebuconazole respectively. Each level had triplicate groups. We did the procedure in steps to ensure that soils were treated homogeneously. The $500 \mathrm{~g}$ of airdried soil was spiked with $100 \mathrm{~mL}$ racemic stock solutions of 1000 and $5000 \mathrm{mg} / \mathrm{L}$ tebuconazole respectively and mixed thoroughly. After solvent evaporation, $4.5 \mathrm{~kg}$ of the untreated soil was added to each spiked soil and then mixed thoroughly. The soil was stationarily incubated for 2 days before the experiment. Pure water was added to restore $25 \%$ water content. Earthworms were allowed to live in the uncontaminated soil one week to acclimate before they were introduced. After their gut contents depurated on moist filter paper for $3 \mathrm{hr}$ at $20^{\circ} \mathrm{C}, 120$ mature earthworms were put into the contaminated soil in each group. The exposure experiment was carried out in glass boxes in manmade climate equipment. The loss of water by evaporation was compensated by addition of pure water every two days. The temperature was set at $20^{\circ} \mathrm{C}$ and the humidity $50 \%$. The 5 earthworms as well as soil (10 g wet soil) were collected after exposure periods $(0.25,0.5,1,3,5,7,10$, 14, 22, 36 days). Earthworms were rinsed by pure water and placed at moist filter paper to depurate most of their gut contents for about $3 \mathrm{hr}$. After that, earthworms were dried with clear filter paper, and then both earthworms and soil were weighed and put into sample bags to freeze at $-20^{\circ} \mathrm{C}$.

\subsubsection{Soil sample treatment}

Soil samples were mixed with $5 \mathrm{~g}$ anhydrous sodium sulfate and $25 \mathrm{~mL}$ acetonitrile in a $50-\mathrm{mL}$ polypropylene centrifuge tube. The tube was stirred for $3 \mathrm{~min}$ on a vortex mixer, exposed to ultrasonic vibration for $10 \mathrm{~min}$ and then centrifuged at $3000 \mathrm{r} / \mathrm{min}$ for $5 \mathrm{~min}$. The extraction was repeated again following the same step. The extracts were combined and then filtered through anhydrous sodium sulfate $(5 \mathrm{~g})$ for dehydration and evaporated to dryness on a vacuumed rotary at $45^{\circ} \mathrm{C}$. The residue was reconstituted in $1 \mathrm{~mL}$ of 2-propanol and filtered through a $0.22-\mu \mathrm{m}$ filter prior to HPLC analysis.

\subsubsection{Earthworm sample treatment}

Before treated with extractants, earthworm samples were thawed for $10 \mathrm{~min}$ at room temperature. They were blended with $15 \mathrm{~mL}$ acetonitrile in a $50-\mathrm{mL}$ polypropylene centrifuge tube and homogenized with IKA Turax T25 homogenizer at $13,600 \mathrm{r} / \mathrm{min}$ for $1 \mathrm{~min}$. The mixture was vortex-mixed for $3 \mathrm{~min}$, exposed to ultrasonic vibration for $10 \mathrm{~min}$ and then centrifuged at $3000 \mathrm{r} / \mathrm{min}$ for $5 \mathrm{~min}$. The supernatants were transferred to a separatory funnel.
The sample was re-extracted in the same way and the supernatants were combined. Next, $3 \times 20 \mathrm{~mL} n$-hexane was added for liquid-liquid partition to extract most of lipid. The upper layer of $n$-hexane was discarded, and the layer of acetonitrile was passed through a funnel with about $15 \mathrm{~g}$ anhydrous sodium sulfate to round bottom flask to evaporate to dryness at $40^{\circ}$. After that, the residue was purified by florisil-SPE cartridge $(1 \mathrm{~g}, 6 \mathrm{~mL}$, Dikma, USA). The cartridge was preconditioned by rinsing with 5 $\mathrm{mL}$ acetone followed by $5 \mathrm{~mL}$ petroleum ether and $5 \mathrm{~mL}$ acetone-petroleum $(1: 9, V / V)$. The sample of dry extract was dissolved in $3 \times 1 \mathrm{~mL}$ of acetone-petroleum $(1: 9, V / V)$, and transferred into the cartridge. The eluate was discarded. Then the SPE cartridge was eluted with additional $5 \mathrm{~mL}$ acetone-petroleum $(1: 2, V / V)$ and the eluate was collected into a clear flask and evaporated to dryness at $40^{\circ} \mathrm{C}$. Finally the residue in the flask was dissolved by 1.0 $\mathrm{mL}$ of 2-propanol for HPLC determination or $1.0 \mathrm{~mL} \mathrm{CE}$ $\mathrm{BGE}$ for CE determination.

\section{Results and discussion}

\subsection{Method development}

\subsubsection{Optimization of CE separation of tebuconazole}

$\beta$-Cyclodextrin $(\beta-\mathrm{CD})$ and its derivatives 2 'hydroxypropyl- $\beta$-cyclodextrin $\quad(\mathrm{HP}-\beta-\mathrm{CD}) \quad$ and sulfated- $\beta$-cyclodextrin $(\mathrm{S}-\beta-\mathrm{CD})$ were evaluated as chiral selectors. In phosphate buffers ( $\mathrm{pH} 1.87,2.16$, 3.79 ) containing $\beta-C D$ and $H P-\beta-C D$, no enantiomeric separation was observed, which may due to the weak basicity of tebuconazole (Wu et al., 2001). The negatively charged $S-\beta-C D$ could provide stronger interactions of coulombic forces, hydrogen bond and steric hindrances (Berthod, 2009) with tebuconazole than $\beta$-CD and HP- $\beta$ $\mathrm{CD}$, leading to a better chiral recognition. Electroosmotic flow (EOF) was minimized in fused-silica capillary at low $\mathrm{pH}(\mathrm{pH}<3)$, which decreased the migration time toward the anode inlet. Thus, $1 \% \mathrm{~S}-\beta-\mathrm{CD}$ was selected as chiral selector, $20 \mathrm{mmol} / \mathrm{L} \mathrm{KH}_{2} \mathrm{PO}_{4}$ was selected as BGE, and 10 $\mathrm{mmol} / \mathrm{L}$ phosphate was used to adjust $\mathrm{pH}$ to 2.16 initially. A reversed separation voltage of $25 \mathrm{kV}$ was employed. Enantiomers were separated at this condition (Fig. 2a).

Two additives of SDS and urea were then selected to enhance the solubility of tebuconazole in buffer. The 10, 50, and $100 \mathrm{mmol} / \mathrm{L} \mathrm{SDS}$ was added to the running buffer and no enantiomeric separation was found and only one sharp peak of the racemate was observed at about $3 \mathrm{~min}$ (Fig. 2c). While 1,2 , and $4 \mathrm{~mol} / \mathrm{L}$ urea was added to the running
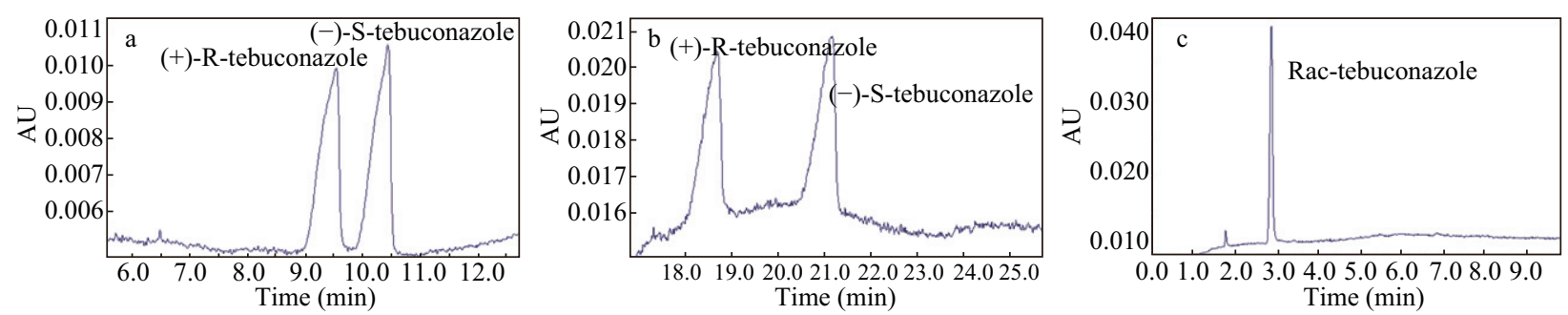

Fig. 2 Optimization of tebuconazole enantioseparation in CE. (a) buffer containing $1 \% \mathrm{~S}-\beta-\mathrm{CD}, 20 \mathrm{mmol} / \mathrm{L} \mathrm{KH}_{2} \mathrm{PO}$, $10 \mathrm{mmol} / \mathrm{L} \mathrm{phosphate;} \mathrm{(b)}$ addition of $2 \mathrm{~mol} / \mathrm{L}$ urea; (c) addition of $50 \mathrm{mmol} / \mathrm{L}$ sodium dodecyl sulfate (SDS). 
Table 1 Comparison of CE and HPLC method in the determination of tebuconazole enantiomers in earthworm samples

\begin{tabular}{llllllllll}
\hline & & RT & $a$ & $b$ & $r^{2}$ & $R_{\mathrm{S}}$ & $\begin{array}{l}\text { LOD } \\
(\mathrm{mg} / \mathrm{L})\end{array}$ & $\begin{array}{l}\text { RSD (\%) } \\
(n=3)\end{array}$ & $\begin{array}{l}\text { Linearity } \\
\text { range }(\mathrm{mg} / \mathrm{kg})\end{array}$ \\
\hline CE & (+)-R-tebuconazole & 19.62 & 1287.0 & 204.31 & 0.983 & 2.14 & 0.13 & 6.7 & $2.9-102.4$ \\
& (-)-S-tebuconazole & 22.15 & 1354.1 & 361.58 & 0.984 & & 0.17 & 5.7 & $70.3-107.7$ \\
HPLC & (-)-S-tebuconazole & 20.19 & 23.12 & -3.91 & 0.999 & 2.79 & 0.021 & 1.3 & $0.56-1000$ \\
& (+)-R-tebuconazole & 26.21 & 22.89 & -3.41 & 0.999 & & 0.023 & 0.9 & $0.56-1000$ \\
\hline
\end{tabular}

$\mathrm{RT}$ is migration time for CE and retention time for HPLC.

buffer containing $1 \% \mathrm{~S}-\beta-\mathrm{CD}, 20 \mathrm{mmol} / \mathrm{L} \mathrm{KH}_{2} \mathrm{PO}_{4}$ and 10 $\mathrm{mmol} / \mathrm{L}$ phosphate, current was inhibited and the migration time exhibited significant increase. Migration time as well as resolution doubled when $2 \mathrm{~mol} / \mathrm{L}$ urea was added (Fig. 2b). Maximum detection concentration was enhanced from $50-100 \mathrm{mg} / \mathrm{kg}$ to over $100 \mathrm{mg} / \mathrm{kg}$. Thus, a solution of $1 \% \mathrm{~S}-\beta-\mathrm{CD}, 20 \mathrm{mmol} / \mathrm{L} \mathrm{KH}_{2} \mathrm{PO}_{4}, 10 \mathrm{mmol} / \mathrm{L}$ phosphate and $2 \mathrm{~mol} / \mathrm{L}$ urea was employed as buffer in CE separation.

\subsubsection{Optimization of SPE clear-up}

The complicated matrix of earthworms might disturb CE and HPLC separations. In order to meet the requirements of both CE and HPLC analysis, further clear-up was introduced. Solid phase extraction (SPE) was evaluated to exploit the polarity difference between matrix and tebuconazole. Florisil, neutral alumina, and pesticarb/ $\mathrm{NH}_{2}$ cartridges (Agela, China) were evaluated in normal phase mode with elution of analyte achieved using solvents of higher polarity than the solvent in which the analyte was transferred into the cartridge. After dry extract was dissolved in $3 \times 1 \mathrm{~mL}$ of acetone-petroleum ether $(1: 9, \mathrm{~V} / \mathrm{V})$ and transferred into the cartridge, $5 \mathrm{~mL}$ solvent was used to elute the analyte. Neutral alumina required acetonepetroleum ether $(1: 1, V / V)$ to elute all the analyte, while florisil required the less polar solvent (acetone-petroleum ether $(1: 2, V / V))$. Pesticarb/ $\mathrm{NH}_{2}$ has the strongest retention on tebuconazole, and even with the pure acetone, there were still 10\%-25\% tebuconazole retained in the cartridge.

Florisil was the preferred absorbent as it provided maximum removal of interfering coextractives with the least loss among the three cartridges, so that samples were suitable for both CE and HPLC determination.

\subsubsection{Comparison between CE separation and HPLC separation}

The HPLC chiral separation method for tebuconazole was developed on ChiralPAK IC with $n$-hexane and 2propanol $(90: 10, V / V)$ as mobile phase (detected at 220

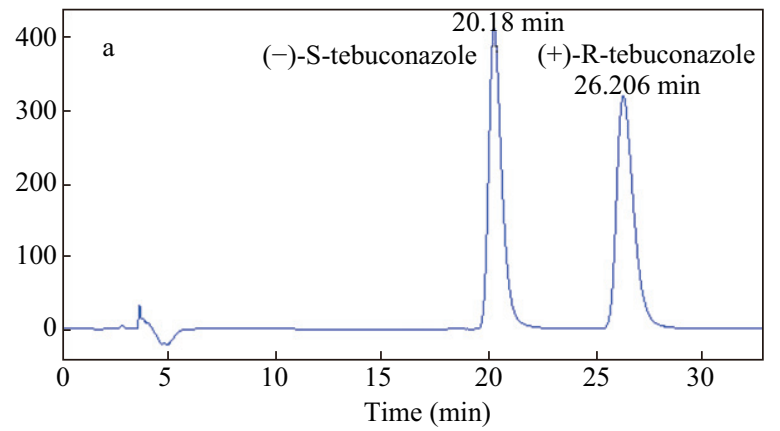

$\mathrm{nm})$. Several key parameters of CE and HPLC separation of tebuconazole were compared (Table 1). The elution orders of right and left-rotation enantiomers in HPLC method were measured by Chiralyser-MP optical rotation detector produced by IBZ Messtechnik Company (Germany). The optical signals were received and processed by Beijing Separation Science \& Technology Development Co., Ltd. (China). The result showed that the first eluted enantiomer was laevo (-)-S-tebuconazole and the second eluted enantiomer was dextro (+)-R-tebuconazole (Fig. 3). The migration orders in CE method were then identified by HPLC orders, which was opposite to the elution orders of HPLC.

RT is the migration time for $\mathrm{CE}$ and retention time for HPLC. Calibration curves are expressed as regression lines $(y=a x+b)$, where, $y$ is the ratio of the peak area of enantiomeric compound, $x(\mathrm{mg} / \mathrm{L})$ is enantiomer concentration, $a$ is slope, $b$ is intercept, and $r^{2}$ is the correlation coefficient. The resolution for a pair of enantiomers was calculated as $R_{\mathrm{S}}$ (Eq. (1)).

$R_{\mathrm{S}}=\frac{2\left(\mathrm{RT}_{2}-\mathrm{RT}_{1}\right)}{\omega_{1}+\omega_{2}}$

where, $\omega$ is the width of the peak at the baseline. LODs, recoveries, RSDs and calibration curves for both tebuconazole enantiomers are shown in Table 1.

Both CE and HPLC have excellent resolution and recovery, but HPLC has lower LOD. Moreover, low solubility of tebuconazole in BGE and the instability $\mathrm{CE}$ itself result in narrow linearity range and large RSD. All real earthworm samples were detected by HPLC initially and CE method was then used as a validation.

\subsection{Enantioselective degradation in soil}

To investigate enantioselective bioaccumulation in earthworms, enantiometric changes in soil was evaluated firstly. The enantiometric ratio $\left(R_{\mathrm{e}}\right)$ (Yi et al., 2007) was employed

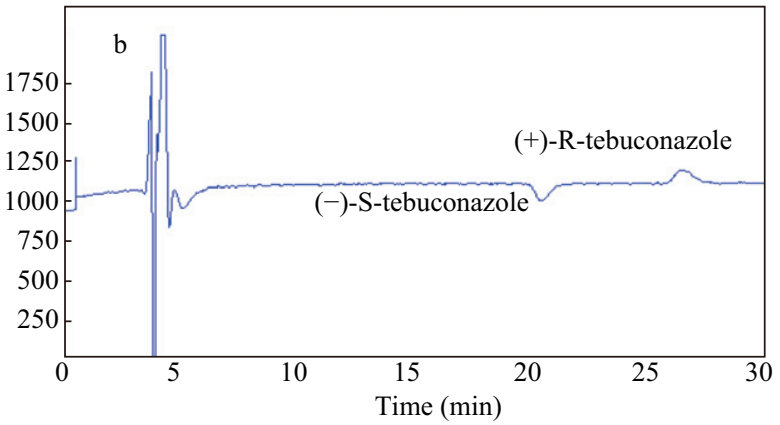

Fig. 3 UV detection and optical detection of two enantiomers of tebuconazole. (a) UV detection of HPLC method; (b) optical detection (Chiralyser optical detector). Flow rate: $1 \mathrm{~mL} / \mathrm{min}, \mathrm{UV}: 220 \mathrm{~nm}, n$-hexane/2-propanol = 90/10 $(\mathrm{V} / \mathrm{V})$. 
to evaluate the enantioselectivity of two enantiomers during the experiments (Eq. (2)).

$R_{\mathrm{e}}=A_{1}-A_{2}$

where, $A_{1}$ is the peak area of (-)-S-tebuconazole, $A_{2}$ is that of (+)-R-tebuconazole and $R_{\mathrm{e}}=1$ represents the racemic mixture. $R_{\mathrm{e}}$ values were all average values of the triplicate in this study.

Concentrations and $R_{\mathrm{e}}$ values of two enantiomers in soil during the period of 36 days of incubation are shown in Table 2. Concentration of tebuconazole decreased about $27 \%$ and $17 \%$ at low and high dose soil respectively at the end of 36 days exposure. The decrease may result from degradation and biotransformation (Bending et al., 2007). No significant difference was observed between the two enantiomers in both low and high dose soil.

\subsection{Enantioselective bioaccumulation in earthworms}

Concentrations of tebuconazole enantiomers in exposed earthworm increased in the initial days as shown in Fig. 4. The increase rates were different from concentration to concentration, and from enantiomer to enantiomer. (+)R-tebuconazole in low dose group experienced a steady increase and reached equilibrium at 3-day-point at 13.08 $\mathrm{mg} / \mathrm{kg}$. From 14 days to 36 days, the concentration had a slightly decline, which may due to the concentration decline in soil. In high dose group, equilibrium came later until 7 days with concentration staying at around 100 $\mathrm{mg} / \mathrm{kg}$. Concentrations of (-)-S-tebuconazole in low dose group surged rapidly to $8.78 \mathrm{mg} / \mathrm{kg}$ at 0.5 days and then slightly increased to peak at $9.90 \mathrm{mg} / \mathrm{kg}$. From that time, concentration began to decrease and the concentration was only around $3 \mathrm{mg} / \mathrm{kg}$ after 22 days exposure. In high dose group, (-)-S-tebuconazole stopped increase at 1 day and turned to drop consistently. At 29 day point, the concentration was the minimum only $7.63 \mathrm{mg} / \mathrm{kg}$.

Organic pollutants were assumed to be partitioned between soil and earthworms (Connell and Markwell, 1990; Krauss et al., 2000). Equilibrium partitioning theory (EPT) model was introduced to describe the uptake process of tebuconazole enantiomers (Connell and Markwell, 1990; Krauss et al., 2000). The uptake of tebuconazole enantiomers are considered to follow a first-order kinetics equation:

$\mathrm{d} C_{\text {Worm }} / \mathrm{d} t=k_{1} C_{\text {Soil }}-k_{2} C_{\text {Worm }}$

$C_{\text {Worm }}=\frac{k_{1} C_{\text {Soil }}}{k_{2}}\left[1-\exp \left(-k_{2} t\right)\right]=K C_{\text {Soil }}\left[1-\exp \left(-k_{2} t\right)\right]$

$K=k_{1} / k_{2}$

where, $t$ is the exposure time, $C_{\text {Worm }}(\mathrm{mg} / \mathrm{kg})$ is the concentration of tebuconazole enantiomers bioaccumulated in earthworm tissues, $C_{\text {Soil }}(\mathrm{mg} / \mathrm{kg} \mathrm{dw})$ is the concentration in

Table 2 Concentrations and $R_{\mathrm{e}}$ values of the two enantiomers in soil during the period of 36 days of incubation

\begin{tabular}{|c|c|c|c|c|c|c|c|c|c|c|}
\hline \multirow{3}{*}{$\begin{array}{l}\text { Time } \\
\text { (day) }\end{array}$} & \multicolumn{4}{|c|}{$10 \mathrm{mg} / \mathrm{kg} \mathrm{dw}$} & \multicolumn{4}{|c|}{$50 \mathrm{mg} / \mathrm{kg} \mathrm{dw}$} & \multicolumn{2}{|c|}{$R_{\mathrm{e}}$} \\
\hline & \multicolumn{2}{|c|}{ (-)-S-tebuconazole } & \multicolumn{2}{|c|}{$(+)$-R-tebuconazole } & \multicolumn{2}{|c|}{ (-)-S-tebuconazole } & \multicolumn{2}{|c|}{$(+)$-R-tebuconazole } & \multirow{2}{*}{$\begin{array}{l}10 \mathrm{mg} / \\
\mathrm{kg} \mathrm{dw}\end{array}$} & \multirow{2}{*}{$\begin{array}{l}50 \mathrm{mg} / \\
\mathrm{kg} \mathrm{dw}\end{array}$} \\
\hline & $\begin{array}{l}\text { Avg. Con.* } \\
\text { (mg/kg dw) }\end{array}$ & RSD (\%) & $\begin{array}{l}\text { Avg. Con. } \\
\text { (mg/kg dw) }\end{array}$ & $\begin{array}{l}\text { RSD (\%) } \\
(n=3)\end{array}$ & $\begin{array}{l}\text { Avg. Con. } \\
\text { (mg/kg dw) }\end{array}$ & $\begin{array}{l}\text { RSD (\%) } \\
(n=3)\end{array}$ & $\begin{array}{l}\text { Avg. Con. } \\
\text { (mg/kg dw) }\end{array}$ & $\begin{array}{l}\text { RSD (\%) } \\
(n=3)\end{array}$ & & \\
\hline 0 & 10.11 & 2.97 & 10.02 & 2.96 & 49.77 & 1.57 & 49.81 & 2.74 & 1.01 & 1.00 \\
\hline 0.25 & 9.72 & 5.92 & 9.71 & 3.87 & 50.47 & 1.67 & 49.89 & 2.15 & 1.00 & 1.01 \\
\hline 0.5 & 10.08 & 3.64 & 10.15 & 2.14 & 50.91 & 3.29 & 50.68 & 3.07 & 0.99 & 1.00 \\
\hline 1 & 9.61 & 2.38 & 9.65 & 1.06 & 48.85 & 4.11 & 48.91 & 5.13 & 1.00 & 1.00 \\
\hline 3 & 9.75 & 2.84 & 9.61 & 2.05 & 47.80 & 5.47 & 47.97 & 5.63 & 1.01 & 1.00 \\
\hline 5 & 9.29 & 2.74 & 9.36 & 2.95 & 47.27 & 3.04 & 47.35 & 2.78 & 0.99 & 1.00 \\
\hline 7 & 8.88 & 2.55 & 8.80 & 3.34 & 46.69 & 13.14 & 46.35 & 3.13 & 1.01 & 1.01 \\
\hline 10 & 8.43 & 5.98 & 8.37 & 2.78 & 45.64 & 5.26 & 45.37 & 2.17 & 1.01 & 1.01 \\
\hline 14 & 8.28 & 4.00 & 8.29 & 3.45 & 45.01 & 4.21 & 44.89 & 4.75 & 1.00 & 1.00 \\
\hline 22 & 7.91 & 4.63 & 7.94 & 6.78 & 43.00 & 2.31 & 42.38 & 5.35 & 1.00 & 1.01 \\
\hline 29 & 7.80 & 3.15 & 7.72 & 3.56 & 42.55 & 5.08 & 42.48 & 4.76 & 1.01 & 1.00 \\
\hline 36 & 7.40 & 4.33 & 7.28 & 4.14 & 41.84 & 3.93 & 41.89 & 2.16 & 1.02 & 1.00 \\
\hline
\end{tabular}

* Avg. Con. represents average concentration.
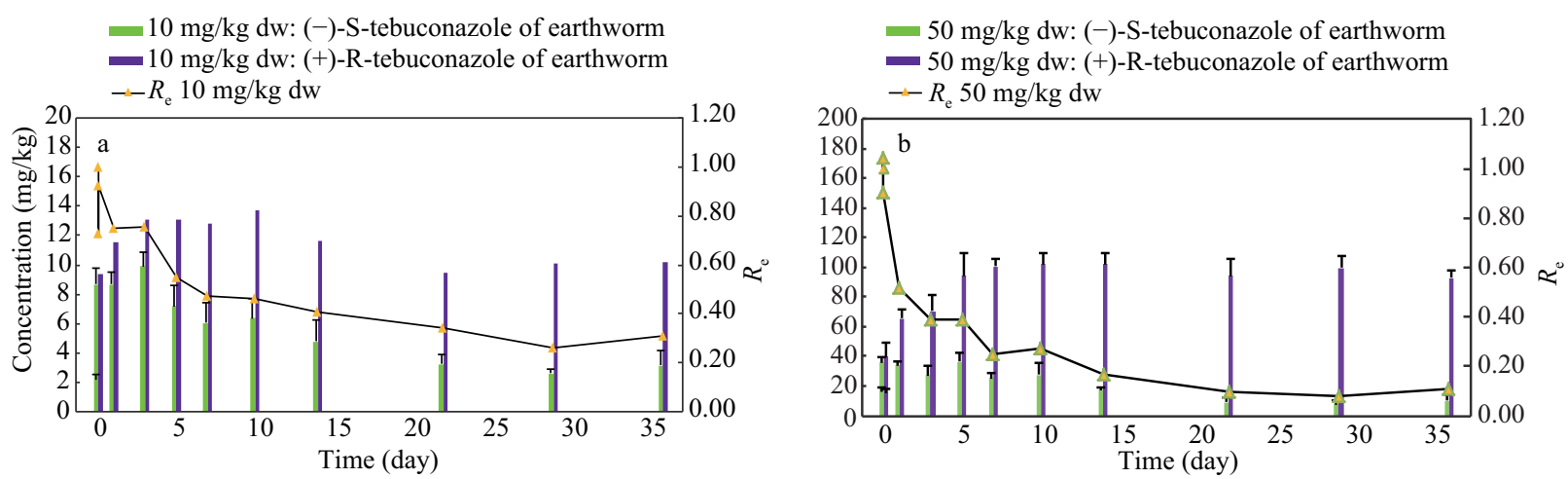

Fig. 4 Concentrations of tebuconazole enantiomers in earthworm samples and $R_{\mathrm{e}}$ values. (a) $10 \mathrm{mg} / \mathrm{kg} \mathrm{dw}$ exposure group (b) $50 \mathrm{mg} / \mathrm{kg} \mathrm{dw}$ exposure group. Data are expressed as mean \pm SD. 
Table 3 Calculated uptake rate coefficient $\left(k_{1}\right)$, elimination rate coefficient $\left(k_{2}\right), K$ and $r^{2}$ of tebuconazole enantiomers in low and high dose exposure

\begin{tabular}{|c|c|c|c|c|c|}
\hline & & $K$ & $k_{1}$ & $k_{2}$ & $r^{2}$ \\
\hline \multirow[t]{2}{*}{$10 \mathrm{mg} / \mathrm{kg} \mathrm{dw}$} & (-)-S-tebuconazole & $1.402 \pm 0.082$ & $2.445 \pm 0.520$ & $1.744 \pm 0.371$ & 0.969 \\
\hline & $(+)$-R-tebuconazole & $0.831 \pm 0.121$ & $1.662 \pm 0.432$ & $1.953 \pm 0.521$ & 0.734 \\
\hline \multirow[t]{2}{*}{$50 \mathrm{mg} / \mathrm{kg} \mathrm{dw}$} & (-)-S-tebuconazole & $1.916 \pm 0.145$ & $1.760 \pm 0.433$ & $0.919 \pm 0.226$ & 0.942 \\
\hline & (+)-R-tebuconazole & $0.548 \pm 0.132$ & $1.924 \pm 11.9$ & $3.511 \pm 21.7$ & 0.222 \\
\hline
\end{tabular}

soil, $k_{1}\left(\right.$ day $\left.^{-1}\right)$ denotes the uptake rate constant from soil, and $k_{2}\left(\right.$ day $\left.^{-1}\right)$ denotes the elimination rate constant, $K$ is the constant ratio of $k_{1}$ and $k_{2}$.

By fitting the average concentrations of triplicate in earthworm and time into Eq. (4), a nonlinear dynamic fitting technique provided by SigmaPlot (SPSS Science, Chicago, IL, USA) gave the estimated value of $K$ and $k_{2}$ (Table 4). $k_{1}$ was calculated with Eq. (5). The treads of $(+)$-R-tebuconazole increase fitted the first-order kinetics well under both high and low concentration groups $\left(r^{2}=\right.$ $0.97,0.94)$. This result indicated that $(+)$-R-tebuconazole in earthworms was proportional to the concentration in soil and accumulation from soil by earthworms was primarily an equilibrium partition process driven by fugacity (Liang et al., 2010). However, (-)-S-tebuconazole does not obey the first-order kinetics under both high and low concentration exposure $\left(r^{2}=0.75,0.22\right)$. It was suggested that the accumulation of (-)-S-tebuconazole by earthworm was more complicated than the equilibrium partition possess. Considering that the enantiomers of tebuconazole were of the same physicochemical properties, and (-)-Stebuconazole might have processed biotransformation and metabolism beyond the equilibrium partition of (+)-Rtebuconazole.

Since the uptake kinetics of tebuconazole enantiomers was different, the uptake of tebuconazole had significant enantioseletivity as shown in Fig. 4. In low dose group (Fig. 4a), $R_{\mathrm{e}}$ dropped during the whole exposure time and stayed around 0.30 at the end of the exposure. This result suggested that the accumulation of tebuconazole in earthworm tissues was enantioselective with preferential accumulation of $(+)$-R-tebuconazole. In high dose group (Fig. 4b), preferential accumulation of (+)-R-tebuconazole was even stronger, and $R_{\mathrm{e}}$ decreased to only 0.11 at the end of the exposure.

In this study, biota to soil accumulation factor (BSAF) was used to express the bioaccumulation of tebuconazole enantiomers. In order to compare with cases in former literatures, the activities were normalized to lipid content of earthworm and organic carbon (OC) of soil, assuming a lipid content of $1 \%$ and a factor of 1.7 between $O C$ and organic matter (OM) (Jager et al., 2003). The Eqs. (6) and (7) are as follows (Xu et al., 2011):

$\mathrm{BSAF}=C_{\mathrm{EW}} / C_{\mathrm{S}}$

or

$\mathrm{BSAF}=C_{\mathrm{EW}} F_{\mathrm{OM}}($ soil $) / 1.7 C_{\mathrm{S}} F_{\text {lip }}($ earthworm $)$

where, $C_{\mathrm{EW}}$ and $C_{\mathrm{S}}$ are concentrations of tebuconazole enantiomers in earthworm and soil respectively. $F_{\mathrm{OM}}$ (soil) is fraction of OM in soil and $F_{\text {lip }}$ (earthworm) is fraction of lipid in earthworm. A measure of BSAF in (Eq. (7)) is $\mathrm{kg} \mathrm{OC} / \mathrm{kg}$ lip. The calculated BSAFs of two enantiomers are shown in Fig. 5.

Armitage and Gobas (2007) pointed out that chemicals with a $K_{\mathrm{OA}}$ (octanol-air coefficient) $\geqslant 10^{5.25}$ and a $K_{\mathrm{OW}}$ (octanol-water coefficient) between $10^{1.75}$ and $10^{12}$ have a biomagnification potential in the soil-earthworm-shrew food-chain unless they are metabolized at a sufficiently rapid rate. The constant $K_{\mathrm{OA}}$ was estimated from the ratio of the dimensionless constants $K_{\mathrm{OW}}\left(K_{\mathrm{OW}}=10^{3.7}\right.$ for tebuconazole)) according to correlation:

$K_{\mathrm{OA}}=K_{\mathrm{OW}} \mathrm{RT} / H$

where, $H$ represents Henry's law constant. $K_{\mathrm{OA}}$ of tebuconazole was then obtained as $10^{15.7}$. Therefore, tebuconazole is expected to have biomagnification potential in the earthworm food chain by this theory. The theory has the assumption that elimination in earthworm was considerably low. (+)-R-tebuconazole was accumulated in the earthworm body with BSAF value of $1.64 \mathrm{~kg}$ $\mathrm{OC} / \mathrm{kg}$ lip in $10 \mathrm{mg} / \mathrm{kg} \mathrm{dw}$ exposure group and 2.61 $\mathrm{kg} \mathrm{OC} / \mathrm{kg}$ lip in $50 \mathrm{mg} / \mathrm{kg} \mathrm{dw}$ exposure group after 36 days. It was suggested that (+)-R-tebuconazole might have biomagnifying effect potential (BSAF $>1 \mathrm{~kg}$ OC/kg lip) in the earthworm food chain, which was up to expectation. Compared with (+)-R-tebuconazole, (-)-S-tebuconazole was less strongly accumulated in the earthworm tissues, of

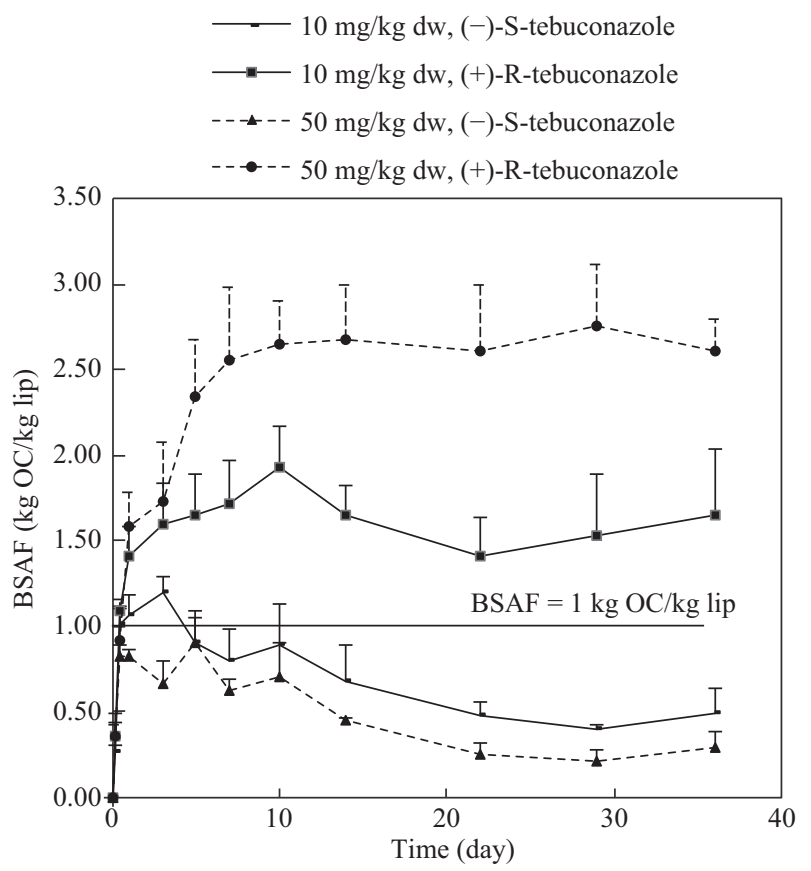

Fig. 5 Calculated BSAFs of two enantiomers in low and high dose exposure. Data are expressed as mean \pm SD. 
which BSAF values were $0.50 \mathrm{~kg}$ OC/ $\mathrm{kg}$ lip $(10 \mathrm{mg} / \mathrm{kg} \mathrm{dw}$ tebuconazole exposure) and $0.28 \mathrm{~kg} \mathrm{OC} / \mathrm{kg}$ lip $(50 \mathrm{mg} / \mathrm{kg}$ $\mathrm{dw}$ tebuconazole exposure) after 36 days.

\section{Conclusions}

Enantioselective analytical method of tebuconazole enantiomers was established and applied in the earthworm bioaccumulation experiment. The uptake kinetics of (+)R-tebuconazole fitted the first-order kinetics well, while (-)-S-tebuconazole did not obey. Bioaccumulation of tebuconazole in earthworm tissues was enantioselective with a preferential accumulation of (+)-R-tebuconazole. In addition, (+)-R-tebuconazole might have biomagnifying effect potential (BSAF $>1 \mathrm{~kg} \mathrm{OC} / \mathrm{kg}$ lip) in this experiment, while (-)-S-tebuconazole did not have biomagnifying effect.

\section{Acknowledgments}

This work was supported by the Innovative Program of the Chinese Academy of Sciences (No. KZCX2-YW-JS403) and the National High Technology Research and Development Program (863) of China (No. 2010AA065105).

\section{References}

Armitage J M, Gobas F A P C, 2007. A terrestrial food-chain bioaccumulation model for POPs. Environmental Science $\mathcal{E}$ Technology, 41(11): 4019-4025.

Bending G D, Rodriguez-Cruz M S, Lincoln S D, 2007. Fungicide impacts on microbial communities in soils with contrasting management histories. Chemosphere, 69(1): $82-88$.

Berthod A, 2009. Chiral recognition mechanisms with macrocyclic glycopeptide selectors. Chirality, 21(1): 167-175.

Connell D W, Markwell R D, 1990. Bioaccumulation in the soil to earthworm system. Chemosphere, 20(1-2): 91-100.

Diao J L, Xu P, Liu D H, Lu Y L, Zhou Z Q, 2011. Enantiomer-specific toxicity and bioaccumulation of alphacypermethrin to earthworm Eisenia fetida. Journal of Hazardous Materials, 192(3): 1072-1078.

Hegeman W J, Laane R W, 2002. Enantiomeric enrichment of chiral pesticides in the environment. Reviews of
Environmental Contamination and Toxicology, 173: 85-116.

Jager T, Fleuren R H L J, Hogendoorn E A, de Korte G, 2003. Elucidating the routes of exposure for organic chemicals in the earthworm, Eisenia andrei (Oligochaeta). Environmental Science $\mathcal{E}$ Technology, 37(15): 3399-3404.

Jager T, van der Wal L, Fleuren R H, Barendregt A, Hermens $\mathrm{J}$ L, 2005. Bioaccumulation of organic chemicals in contaminated soils: evaluation of bioassays with earthworms. Environmental Science E Technology, 39(1): 293-298.

Kaulen J, 1989. Die enantiomere des azolfungizids HWG-1608-asymmetrische synthese eines 2-hydroxyethylazolfungizids. Angewandte Chemie, 101(4): 507-508.

Krauss M, Wilcke W, Zech W, 2000. Availability of polycyclic aromatic hydrocarbons (PAHs) and polychlorinated biphenyls (PCBs) to earthworms in urban soils. Environmental Science $\mathcal{E}$ Technology, 34(20): 4335-4340.

Liang X W, Zhu S Z, Chen P, Zhu L Y, 2010. Bioaccumulation and bioavailability of polybrominated diphenyl ethers [corrected] (PBDEs) in soil. Environmental Pollution, 158(7): 2387-2392.

Shen Z G, Zhu W T, Liu D H, Xu X Y, Zhang P, Zhou Z Q, 2012. Stereoselective degradation of tebuconazole in rat liver microsomes. Chirality, 24(1): 67-71.

Wang X Q, Wang X S, Zhang H, Wu C X, Wang X Y, Xu H et al., 2012. Enantioselective degradation of tebuconazole in cabbage, cucumber, and soils. Chirality, 24(2): 104-111.

Williams A, 1996. Opportunities for chiral agrochemicals. Pesticide Science, 46(1): 3-9.

Wu Y S, Lee H K, Li S F, 2001. High-performance chiral separation of fourteen triazole fungicides by sulfated betacyclodextrin-mediated capillary electrophoresis. Journal of Chromatography A, 912(1): 171-179.

Xu P, Diao J L, Liu D H, Zhou Z Q, 2011. Enantioselective bioaccumulation and toxic effects of metalaxyl in earthworm Eisenia foetida. Chemosphere, 83(8): 1074-1079.

Xu P, Liu D H, Diao J L, Lu D H, Zhou Z Q, 2009. Enantioselective acute toxicity and bioaccumulation of benalaxyl in earthworm (Eisenia fedtia). Journal of Agricultural and Food Chemistry, 57(18): 8545-8549.

Yi F, Guo B Y, Peng Z L, Li H F, Marriott P, Lin J M, 2007. Study of the enantioseparation of imazaquin and enantioselective degradation in field soils by CZE. Electrophoresis, 28(15): 2710-2716.

Zhu W T, Qiu J, Dang Z H, L C G, Jia G F, Li L et al., 2007. Stereoselective degradation kinetics of tebuconazole in rabbits. Chirality, 19(2): 141-147. 